\title{
THE LEGAL EFFECT OF VOLUNTARY SELF-EXCLUSION PROGRAMS FOR Problem Gamblers*
}

\section{NATALIA ANTOLAK-SAPER}

The voluntary self exclusion program has been designed as one attempt to minimise the harm caused by problem gambling and electronic gaming machines. However, the program's role as a genuine regulatory response is questionable. Few reporting requirements for gaming corporations and a reliance on an unsophisticated method of detecting self-excluded problem gamblers significantly undermine the purpose of the program. This paper considers the liability of gaming venues and corporations in circumstances where a self-excluded problem gambler has not been successfully excluded from the gaming venue. It is suggested that, in entering into the program, a problem gambler may be under a reasonable expectation that the gaming venue will assist in his or her endeavour to control the problematic gambling. Drawing primarily on the laws of Victoria, this article will discuss how the voluntary self-exclusion program is in need of reform so that it can better act as a harm minimisation mechanism. Further, the article will explore possible legal redress in contract, equity and under the Trade Practices Act 1974 (Cth), for problem gamblers who have participated in an ineffective voluntary self-exclusion program.

\section{INTRODUCTION}

In October 2009, the Productivity Commission published a draft report, entitled Gambling, providing an update on developments that have occurred within the gambling industry since the Productivity Commission's report, Australia's Gambling Industries, published in 1999. ${ }^{1}$ The draft report

\footnotetext{
*BA, LLB(Hons), Monash University. The author wishes to thank Dr Jeannie Marie Paterson, Melbourne Law School, for her helpful comments, insights and guidance on this article. Any errors remain those of the author.

${ }^{1}$ At the time of writing, the Productivity Commission had sent a final report to the Australian Government for its consideration on the 26 February 2010. The report is yet to be released. See Productivity Commission, Gambling - Public Inquiry (23 June 2010) Australian
} 
considers a range of issues, including: the nature and definition of gambling; the participation in gambling, with a particular emphasis on problem gamblers; the economic and social impacts of the gambling industries; and the effects of the regulatory structure. In its 2009 Gambling report, the Productivity Commission places particular emphasis on electronic gaming machines (EGMs), which the Commission found accounted for around three quarters of the cases of severe problem gambling. ${ }^{2}$ At the time of the draft report, it was noted that there were approximately 198303 EGMs nationally that caused 85 per cent of problem gambling. ${ }^{3}$ Further, the Commission found that two thirds of gaming losses - about $\$ 12$ billion a year - occurred on EGMs. Perhaps what is most concerning is that the report identified that about 40 per cent to50 per cent of EGM revenue comes from problem gamblers. This means that almost half of the revenue generated by EGMs is as a result of the serious gambling addiction of approximately 1 per cent to 3 per cent of Australia's public.

The Productivity Commission's 2009 draft report builds on concerns that have repeatedly been raised in regard to the socially detrimental impact of EGMs. In particular, the now infamous article, Gambling with People's Lives, published in The Age in 2003, reported that Tattersalls, a leading gaming corporation, was deliberately targeting problem gamblers in Victoria. ${ }^{4}$ The article alleged that, according to data gathered by Tattersalls, 15 per cent of those who play on EGMs do so excessively, and are responsible for 57 per cent of the gaming corporation's revenue. Further, it was reported that a leaked Tattersalls' document acknowledged this gross disparity between the percentages by stating that '[w]e derive enormous value...from a very small group of customers'. ${ }^{5}$ The document identified this 'very small group of customers' as Tattersalls' target market group. ${ }^{6}$ This 'very small group of customers' who gamble excessively, and on whom gaming corporations are

Government Productvitiy Commission <http://www.pc.gov.au/projects/inquiry/gambling2009>.

${ }^{2}$ Productivity Commission Gambling, Draft Report (2009), 1.3.

3 'Gambling Report Lays Cards on the Table for States' The Age, Melbourne, 23 October 2009, 16.

${ }^{4}$ Anne O’Casey and James Doughney, 'Gambling with People’s Lives', The Age (Melbourne), 15 October 2003, 15. See also James Doughney, 'Ethical Gambling? Not from Tattersalls', The Age (online), 26 March 2004 < http://www.theage.com.au/articles/2004/03/25/ 1079939782618.html>.

${ }^{5}$ O’Casey and Doughney, ‘Gambling with People’s Lives’, above n 4, 15.

${ }^{6}$ O’Casey and Doughney, 'Gambling with People’s Lives', above n 4, 15; Doughney, 'Ethical Gambling?’, above n 4. 
reliant for quite a significant proportion of their profit, might be termed 'problem gamblers' for reasons discussed below.

Concerns over the social issues associated with problem gambling have prompted a range of measures designed to minimise the harm caused by problem gambling. ${ }^{7}$ One such type of measure is the 'voluntary self-exclusion program'. ${ }^{8}$ The basic premise of the voluntary self-exclusion program is that a problem gambler can request to be banned from a gaming venue and/or to be removed from the gaming corporation's mailing list. ${ }^{9}$

This article argues that the efficacy of voluntary self-exclusion programs as a regulatory response to problem gambling is questionable. There are few reporting requirements for gaming corporations administering such programs, which makes it difficult to monitor the effectiveness of the programs. ${ }^{10}$ Further, there are a number of factors that render the current voluntary selfexclusion programs incapable of successfully facilitating the exclusion of problem gamblers. Case law suggests that at least some self-excluded problem gamblers continue to gamble at the venue without being detected. ${ }^{11}$ This is

${ }^{7}$ In Victoria, for example, the state government has specifically endeavoured to address the issue of problem gambling through the introduction of various policies and strategies. These initiatives are wide ranging and include: ensuring a more socially responsible gambling industry, protecting vulnerable communities, and, most importantly, improving consumer protection. For further information see Office of Gaming and Racing, Department of Justice (Vic), Taking Action on Problem Gambling: A Strategy for Combating Problem Gambling in Victoria (2006) ('A Strategy for Combating Problem Gambling’).

${ }^{8}$ Productivity Commission, Australia's Gambling Industries, Inquiry Report No 10 (1999) vol 2 (Part D) ('Australia's Gambling Industries, vol 2') 16.67. See also The South Australian Centre for Economic Studies, 'Evaluation of Self-exclusion Programs and Harm Minimisation Measures: Report A' (Research Report, Adelaide \& Flinders Universities, February 2003 ('Evaluation of Self-exclusion Programs'); Department of Justice (Vic); Taking Action on Problem Gambling: Responsible Gambling Codes of Conduct and Self-Exclusion Programs, (Information Paper, Victorian Government, May 2008) ('Responsible Gaming Codes of Conduct').

${ }^{9}$ See, eg, the Australian Hotels Association Victoria website, which discusses the Selfexclusion Gambling Online (SEGO) program. This program is aimed at individuals who experience problems with gambling: Australia Hotels Association, Self-exclusion (2008) Australia Hotels Association <http://www.ahavic.com.au/selfexclusion.php> ('Selfexclusion'). For an example of a 'Deed of Self-exclusion' see Australia Hotels Association, SEGO - Self Excluded Gamblers Online (2008) Australia Hotels Association $<$ http://www.ahavic.com.au/deed/index.html>.

${ }^{10}$ Evaluation of Self-exclusion Programs, above n 8, vi.

${ }^{11}$ Ibid vii. See, eg, Foroughi v Star City Pty Ltd [2007] FCA 1503 (27 September 2007) ('Foroughi'); Reynolds v Katoomba RSL All Services Club Ltd [2001] NSWCA 234 (20 September 2001) ('Reynolds'); Preston v Star City Pty Ltd [1999] NSWSC 1273 (1 February 2000) [87]. 
unsurprising given that, typically, venues rely only on an unsophisticated method of 'facial recognition' by their employees as a way of detecting banned patrons. ${ }^{12}$ Moreover, as the leaked Tattersalls' document demonstrates, there may be considerable incentives for gaming corporations to encourage the patronage of problem gamblers. Gaming venues may even induce problem gamblers in the program to return to, and gamble at, the venue. $^{13}$

This article considers the circumstances in which a problem gambler who has entered into a voluntary self-exclusion program, but has failed to be excluded from the gaming venue, may be able to bring a private legal action against the gaming corporation seeking compensation for losses incurred as a result of continuing to gamble at the venue. This article argues that there are limited legal responsibilities imposed on gaming corporations and venues in operating voluntary self-exclusion programs. Courts have not been receptive to claims for damages by self-excluded problem gamblers against gaming corporations, emphasising instead the personal responsibility of the problem gambler for his or her gambling losses. The article argues that this approach underestimates the compulsive nature of problem gambling, and places insufficient responsibility on a gaming corporation to implement effective self exclusion programs.

Where a problem gambler enters into a voluntary self-exclusion program, the individual has taken steps to control his or her own gambling, and may have a reasonable expectation that the gaming venue will assist in that task. It is argued that some degree of legal responsibility should be imposed on a gaming corporation that has an inadequate system for identifying participants in its voluntary self-exclusion program, gives a false impression of the effectiveness of that program, or continues to encourage problem gamblers to gamble. This issue of legal responsibility is part of a larger question of how to improve voluntary self-exclusion programs to ensure that they operate as a meaningful regulatory response to problem gambling.

Drawing primarily on the laws of Victoria, this article seeks to demonstrate that the current voluntary self-exclusion program is in need of substantial reform in order to afford the problem gambler adequate protection. Part II of the article begins with a brief examination of problem gambling and the personal and social consequences associated with it. Parts III to IV consider the possibility of a problem gambler, who has participated in an ineffective

\footnotetext{
${ }^{12}$ Evaluation of Self-exclusion Programs, above n 8, vii; see, eg, Foroughi [2007] FCA 1503 (27 September 2007).

${ }^{13}$ See, eg, Kakavas v Crown Ltd [2007] VSC 526 (8 December 2009).
} 
voluntary self-exclusion program, seeking redress for the failure of that program in contract, equity and under the Trade Practices Act 1974 (Cth) ('TPA') for misleading and deceptive conduct and for unconscionable conduct. Several options for reform are suggested in the article. It is hoped that, as a result, the debate can progress to the point where appropriate reform can be implemented.

\section{Problem Gambling}

\section{A Definition}

Over the years, gambling has become an inherent part of Australian culture. ${ }^{14}$ For many members of the population, gambling is 'a generally socially accepted and commercially important leisure activity' ${ }^{15}$ However, in some instances, a person may begin exhibiting frequent, uncontrolled gambling behaviour. Terminology to describe such behaviour has included 'pathological', 'excessive', 'compulsive', 'addictive' and 'problem' gambling. ${ }^{16}$ Problem gambling has also been viewed as a mental disorder. According to the Diagnostic and Statistical Manual of Mental Disorders (DSM IV) of the American Psychiatric Association, problem gambling is:

a progressive behaviour disorder in which an individual has a psychologically uncontrollable preoccupation and urge to gamble. This results in excessive gambling, the outcome of which compromises, disrupts or destroys the gambler's personal life, family relationships or vocational pursuits. These problems in turn lead to intensification of the gambling behaviour. The cardinal features are emotional dependence on gambling, loss of control and interference with normal functioning. ${ }^{17}$

${ }^{14}$ See, eg, Australian Institute for Gambling Research, 'Australian Gambling Comparative History and Analysis' (Project Report, Victorian Casino and Gaming Authority, October 1999) 12-18.

${ }^{15}$ M Dickerson et al, 'Definition and Incidence of Problem Gambling, Including the Socioeconomic Distribution of Gamblers' (Report, Victorian Casino and Gaming Authority, 1997) 103.

${ }^{16}$ Geoffrey T Caldwell et al, 'Social Impact Study, Civic Section 19 Development and Casino: Casino Development for Canberra’ (Social Impact Report, AGPS, 1988) 36; see also Dickerson et al, above n 15.

17 American Psychiatric Association (1995) Diagnostic and Statistical Manual of Mental Disorders, Fourth Edition, American Psychiatric Association, Washington DC, [312.31]. 
The definition provided by the DSM IV has been criticised by some commentators ${ }^{18}$ who argue that it does not allow for the fact that the harm arising out of gambling is contextually based; that is to say, that the harm experienced from gambling will be relative to the individual's personal financial status. ${ }^{19}$

In Australia, problem gambling is most commonly defined in terms of its social impact, rather than through a medical interpretation of the condition as an addiction. ${ }^{20}$ Most notably, it appears that Australia is currently the only country in which a research-based definition is used that makes no reference to diagnostic criteria. ${ }^{21}$ Thus, the Australian Institute for Gambling Research has defined problem gambling as:

the situation when a person's gambling activity gives rise to harm to the individual player, and/or to his or her family, and may extend into the community. ${ }^{22}$

This research-based definition has been adopted by several jurisdictions in Australia. For example, the Casino Control Act 1982 (Qld) states that a problem gambler is someone:

whose behaviour relating to gambling -

(a) is characterised by difficulties in limiting the amount of money or time the person spends on gambling; and

(b) leads to adverse consequences for the person, other persons or the community. ${ }^{23}$

\footnotetext{
${ }^{18}$ See Michael Walker, 'The Medicalisation of Gambling as an "Addiction”' in Jan McMillen (ed), Gambling Cultures: Studies in History and Interpretation (Routledge, 1996), 204, 22439; see also Dickerson et al, above n 15, 104.

${ }^{19}$ Dickerson et al, above n 15, 103.

${ }^{20}$ See, eg, Dickerson et al, above n 15; see also James Doughney, 'Ethical Blindness, EGMs and Public Policy: A Tentative Essay Comparing the EGM and Tobacco Industries' (2007) 5(4) International Journal of Mental Health Addiction 311, 311-319.

${ }^{21}$ Cf South Oaks Gambling Screen and Canadian Problem Gambling Index in The South Australian Centre for Economic Studies, 'Measurement of Prevalence of Youth Problem Gambling in Australia: Report on Review of Literature' (Final Report, Adelaide and Flinders Universities, December 2003), 7-11, 15.

${ }^{22}$ Dickerson et al, above n 15, 106.

${ }^{23}$ Casino Control Act 1982 (Qld) sch 1. For an example of a definition of problem gambling by reference to the examples and behaviours that are related to harm see Gambling and Racing Control (Code of Practice) Regulations 2002 (ACT) sch 1, cl 1.2.
} 
Nevertheless, not all jurisdictions have elected to define problem gambling within legislation. For example, in Victoria, the Casino Control Act 1991 (Vic) ('CCA') does not define the term 'problem gambler' at all. ${ }^{24}$ Some commentators have advocated that, for the purpose of consistency, a national definition should be adopted. ${ }^{25}$ However, since it is beyond the scope of this article to debate whether or not a national definition should be adopted, an extensive discussion of the advantages and disadvantages of doing so is omitted.

The next part of this article will discuss the social and economic impact of problem gambling.

\section{B The Magnitude of Problem Gambling}

Gambling participation in Australia has been described as one of the highest among English-speaking nations. ${ }^{26}$ Nationally, it has been estimated that approximately 3 per cent of the population in Australia are 'problem gamblers ${ }^{27}$ with a further 0.6 per cent being described as 'at risk' of developing gambling problems. ${ }^{28}$ This small percentage of the population contributes to approximately one third of total expenditure on gambling in Australia. ${ }^{29}$ The turnover in the industry is substantial. According to the Productivity Commission's 2009 draft report, Australians spend

\footnotetext{
${ }^{24}$ See also Casino Control Act 1992 (NSW).

${ }^{25}$ Some commentators advocate that problem gambling should be 'characterised by difficulties in limiting money and/or time spent on gambling which leads to adverse consequences for the gambler, others, or for the community'. See Penny Neal, Paul Delfabbro and Michael O'Neil, Problem Gambling and Harm: Towards a National Definition (Report, Department of Justice (Vic), 2005) 124-9.

${ }^{26}$ Dixie Statham, Genetic Epidemiology of Pathological Gambling (March 2004) Genetic Epidemiology, Molecular Epidemiology and Queensland Statistical Genetics Laboratories Studies <http://genepi.qimr.edu.au/studies/ga/?studycode=GA>. For an analysis within the Australian context see also Andrew Worthington et al, 'Gambling Participation in Australia: Findings from the National Household Expenditure Survey’ (2007) 5(2) Review of Economics of the Household 209, 209-21.

${ }^{27}$ See Australian Institute of Criminology and PricewaterhouseCoopers, 'Serious Fraud in Australia and New Zealand' (Research and Public Policy Series, No 48, Australian Institute of Criminology, 2003).

28 See, eg, Australian Institute for Gambling Research, Social and Economic Impacts of Gambling in New Zealand (Final Report, Australian Institute for Gambling Research, July 2001).

29 Yuka Sakurai and Russell Smith, 'Gambling as a Motivation for the Commission of Financial Crime' (Research Paper, No 256, Australian Institute of Criminology, June 2003) $2-3$.
} 
approximately $\$ 18$ billion a year on gambling. ${ }^{30}$ Almost a decade ago, the Australian gambling industry 'generated over $\$ 11$ billion in net takings and $\$ 650$ million in commissions ... for government ${ }^{31}$ and had a turnover of $\$ 94.5$ billion.

In order to better understand the mechanics of the gambling industry, it is useful to consider the state of Victoria in more detail. Victoria has been described as a 'poker machine state' ${ }^{32}$ The gambling industry is dominated by three major gaming corporations - Tabcorp, Tattersalls, and Crown. The revenue generated by gambling losses is dispersed as follows: the state government receives more than one third in taxes, an approximate one third is divided between Tabcorp and Tattersalls, and the remainder is divided between Crown and the (mostly chain-owned) hotels and clubs, in which Tabcorp and Tattersalls place EGMs. ${ }^{33}$

In Victoria, EGMs are known to be specifically targeted at communities of relatively low socioeconomic status (SES). Gaming corporations place more machines per capita in those areas that are known to be of a lower SES than those of higher SES. ${ }^{34}$ During the initial stages of the industry, representatives would openly admit that this was indeed the intention of the gambling service providers. Such representatives described the EGMs as a 'blue collar form of entertainment'. ${ }^{35}$ As a Clubs Victoria representative once stated:

This is a poor man's sport, playing gaming machines. It is simple, unstimulating and non-interactive but more poor, lesser educated like it more than do rich, educated people. ${ }^{36}$

In response to this type of practice, the Victorian Commission for Gambling Regulation $^{37}$ - an independent statutory body responsible for the regulation

\footnotetext{
30 Ross Gittins, 'Growth Comes at a Cost, and Sometimes Happiness Pays' The Age (Melbourne) 28 October 2009, 17.

${ }^{31}$ Productivity Commission, Australia's Gambling Industries, Inquiry Report No 10 (1999) vol 1 (Part A-C) ('Australia's Gambling Industries, vol 1'), 2.10.

32 James Doughney, 'The Poker-machine State in Australia: A Consideration of Ethical and Policy Issues’ (2006) 4(4) International Journal of Mental Health Addiction 351, 351.

${ }^{33}$ Ibid 361.

${ }^{34}$ Australia's Gambling Industries, vol 1, above n 31, [10.1]-[10.5].

${ }^{35}$ James Doughney, The Poker Machine State; Dilemma in Ethics, Economics and Governance (Common Ground Publishing, 2002) 21.

${ }^{36}$ Australia's Gambling Industries, vol 1, above n 34, [10.43].

${ }^{37}$ Gambling Regulation Act 2003 (Vic); Casino Control Act 1991 (Vic); Casino (Management Agreement) Act 1993 (Vic).
} 
of Victoria's gambling industry - imposed significant restrictions on Tabcorp and Tattersalls in respect of the placement of EGMs. Further, in 2006, a 'regional capping' policy ${ }^{38}$ was introduced, a policy that doubled the number of capped regions and extended the boundaries of already existing metropolitan regions. Nineteen regions became capped at 10 EGMs per thousand adults, which resulted in the removal of up to 540 EGMs from low SES communities. ${ }^{39}$ Further, the regions that already had 10 EGMs per thousand adults would be capped at a lower density. However, some commentators maintain that this has made little tangible difference as lower SES communities are still the most vulnerable and experience the most harmful gambling losses. ${ }^{40}$

To further illustrate the magnitude of problem gambling, it is useful to consider the previously discussed information held by Tattersalls - and potentially by Tabcorp - through data collection via respective loyalty membership schemes. When EGMs were still in their relative infancy in the state of Victoria, industry representatives commented that 80 per cent of total losses were derived from 20 per cent of EGM users. ${ }^{41}$ Since then, representatives have ceased making such statements, and it was not until 2003 that subsequent information was made available to the public. In 2003, information was leaked from within Tattersalls concerning data that was collected from a card-based loyalty membership scheme. Such data had been gathered from the 'Tatts Pokies Advantage Program'. The scheme allowed for members' behaviour to be tracked when they used the loyalty card issued under the scheme in any of the venues owned by Tatts. The purpose of the data was to allow better marketing of Tatts venues:

What we must understand is: what do these customers look like? i.e. demographic, behaviours, attitudes and psychographics displayed. Once this is understood, we will know how best to market to these groups and influence their decisions to make Tatts Pokies venues preferred destinations. ${ }^{42}$

\footnotetext{
${ }^{38}$ A Strategy for Combating Problem Gambling, above n 7.

${ }^{39}$ Ibid 4.

${ }^{40}$ See Michael O'Neil et al, Study of the Impact of Caps on Electronic Gaming Machines (Final Report, Department of Justice (Vic), February 2005).

${ }^{41}$ Doughney, above n 32, 360.

42 O’Casey and Doughney, 'Gambling with People’s Lives', above n 4, 15. See also Jonathan Holmens, Interview with Duncan Fisher (Television Interview, Four Corners, 2 October 2003) <http://www.abc.net.au/cgi-bin/common/printfriendly.pl?/4corners/content/2003/ 20031013_georges_gold/int_fischer.htm>.
} 
Further findings from the document included the following:

1. That the data gathered from the card-based loyalty membership scheme was an accurate approximation of EGM users in general, ${ }^{43}$ which allowed for relevant stakeholders to make informed judgments about the industry.

2. That Tattersalls was anxious about revealing such data to regulatory bodies, as it was confident that this information would attract some form of liability. ${ }^{44}$

3. That the purpose of the scheme was to target 'high turnover' users, otherwise known as heavy users, and entice them to remain at the machines longer. ${ }^{45}$

4. That women were the primary focus of marketing initiatives, as it was found that two thirds of the revenue generated by Tatts came from female consumers. Thus, 'promotions should generally not be based on the preferences of male customers'. ${ }^{46}$

5. That consumers were generally in the older age group; in particular, it was found that problem gamblers commonly belonged to the 46-55 year old cohort. ${ }^{47}$

6. That, although those who used EGMs in the daytime did not necessarily lose more than those who did so in the evening, ${ }^{48}$ this did undermine the image promoted by gaming corporations that 'a harmless night out at the pokies' is the main source of the industry's revenue.

The document further indicated that, ' $34 \%$ of members who spend ... greater than $\$ 50$ per visit contribute over $82 \%$ of value'. ${ }^{49}$ Additional evidence revealed that the 15 per cent of heavy gamblers who spend an average of about 150 minutes 'playtime' each visit, will usually visit more than once per

\footnotetext{
${ }^{43}$ Doughney, above n 35, 42.

${ }^{44}$ Ibid.

${ }^{45}$ Ibid 45.

${ }^{46}$ Ibid 26.

${ }^{47}$ Ibid 43.

${ }^{48}$ Ibid 44.

${ }^{49}$ As quoted in Doughney, above n 32, 353.
} 
month and do not restrict their visits to just one venue. ${ }^{50}$ Thus, approximately 60 per cent of losses are derived from 15 per cent of EGM users who lose more than $\$ 100$ every 2 hours. ${ }^{51}$

\section{Voluntary Self-Exclusion Programs}

Voluntary self-exclusion programs in gaming venues may operate as part of a voluntary industry code of practice ${ }^{52}$ or may be mandated by legislation. ${ }^{53}$ The gambling industry in Australia operates pursuant to more than 30 voluntary codes of practice ${ }^{54}$ applying across all states and territories. ${ }^{55}$ Perhaps the most notable code is the Australian Gaming Council Strategy for Responsible Gambling, which applies nationally across Australia. The Code begins by indicating the overarching principles of a voluntary self-exclusion program and then states that:

Venues should be accountable by public reporting of data, that they have adequate staff training and allocation and surveillance to provide a workable infrastructure for gamblers who desire to self-exclude. Accordingly, members of the AGC facilitating self-exclusion will develop systems and programs that seek to meet these principles in consultation with the appropriate treatment services and other relevant stakeholders, and according to their own particular and jurisdictional circumstances. ${ }^{56}$

\footnotetext{
${ }^{50}$ Doughney, above n 35, 45.

${ }^{51}$ Doughney, above n 32, 360-4.

${ }^{52}$ For example, as part of the Gaming Machines Operators Code of Practice, Tabcorp and Tattersalls agree to promote responsible gaming by providing, among other things, the 'availability and promotion of self-exclusion procedures'.

53 See, eg, Casino Control Act 1991 (Vic); Casino Act 1997 (SA); Casino Control Act 1992 (NSW).

${ }^{54}$ See, eg, ACT Gambling and Racing Control Code of Practice (ACT); Tabcorp Responsible Gambling Code of Practice (NSW); Australian Hotels Association (NSW) Responsible Conduct of Gambling (NSW); NT Code of Practice for Responsible Gambling (NT); Queensland Responsible Gambling Code of Practice (Qld); Gaming Machine Venue Code of Practice (SA); Wrest Point Casino Responsible Service of Gaming Policy (Tas); Tabcorp Responsible Gambling Code of Practice (Vic).

55 Australian Gaming Council, 'Responsible Gambling in Australia' (Fact Sheet, AGC FS 22/08, Australasian Gaming Council, November 2008, 1-2.

56 Responsible Gaming Strategy, Australasian Gaming Council <http://www.austgaming council.org.au/images/pdf/resp\%20gamb\%20strat.pdf > 3-5.
} 
In Victoria, there are currently nine ${ }^{57}$ operating codes of practice that are relevant to the gambling industry. In particular, the codes that are most relevant in the context of EGMs and voluntary self-exclusion programs are the Gaming Machines Operators Code of Practice and the Licensed Venue Operators Code of Practice. Pursuant to the Gaming Machines Operators Code of Practice, Tabcorp and Tattersalls agree to promote responsible gaming by providing, among other things, the 'availability and promotion of self-exclusion procedures'. Concurrently, under the Licensed Venue Operators Code of Practice, venue operators undertake:

- To conduct their business in a manner that precludes the following persons from entering their restricted gaming rooms:

... persons known by the venue operator to be participating in a self-exclusion program.

- To assist patrons to whom gaming machine play presents problems by supporting a venue self-exclusion program, displaying signage and brochures promoting accredited counselling services and directing those patrons to avenues of effective support.

The Victorian state government has attempted to implement policies and procedures to ensure that voluntary self-exclusion programs do not operate solely under the Codes, and that the programs operate in such a manner as to adequately achieve harm minimisation objectives. In December 2007, the state government enacted the Gambling Legislation Amendment (Problem Gambling and Other Measures) Act 2007 amending the Gambling Regulation Act 2003, through, inter alia, the introduction of a new provision, section 3.4.12A. Pursuant to this provision, it is a condition of licensing that a gaming venue conducts a voluntary self-exclusion program that has been approved by the Commission. Pursuant to section 10.6.2 a gaming venue is required to comply with several conditions in order to successfully operate a voluntary self-exclusion program. ${ }^{58}$

57 Crown Melbourne Limited Code of Practice and Responsible Gaming Support Centre; Tabcorp Responsible Gambling Code of Practice; Victorian Gaming Machine Industry Accord; Victorian Gaming Machine Industry Advertising Code of Ethics; Licensed Venue Operators Code of Practice; Gaming Machine Operators Code of Practice; Greyhound Racing Victoria Responsible Wagering Code of Practice; Harness Racing Victoria Responsible Wagering Code of Practice; Tattersall's Responsible Gaming Code of Conduct and Tattersall's Lottery Retailer Code of Practice. See, for a list of such codes: $<$ http://www.austgamingcouncil.org.au/images/pdf/Fact_Sheets/agc_fs22respgambling.pdf > .

${ }^{58}$ Gambling Legislation Amendment (Problem Gambling and Other Measures) Act 2007 (Vic), s 10.6.2. 
In 2008, the Victorian Department of Justice published additional draft guidelines and standards for voluntary self-exclusion programs. ${ }^{59}$ These included a direction that a voluntary self-exclusion program must:

a) require the venue operator to take reasonable steps to ensure that a self-excluded person does not enter the gaming machine area of the venue, and

b) detail the procedure that will be adopted to detect self-excluded persons who enter the gaming machine area of the venue. ${ }^{60}$

Typically, more prescriptive legislation applies to Casino operators than to other sorts of gaming venues. Such legislation generally has several common features. The first of these features is the requirement that the Casino operator conduct a formal self-exclusion program. Secondly, the Acts impose minimum requirements in respect of the operation of such programs. The provisions further stipulate that, in instances where a problem gambler is found to be in breach of a self-exclusion program, he or she can be liable to a penalty. It should be noted that legislation governing self-exclusions programs in a casino typically only applies to that casino. Therefore a problem gambler who enters into a self-exclusion program pursuant to such legislation will be excluded from only that casino. This type of arrangement may be contrasted with a Deed of Self Exclusion (discussed below) which permits the problem gambler to nominate several venues from which he or she wishes to be excluded.

In Victoria, the Casino Control Act 1991 (Vic) ('CCA 1991') requires the casino to provide and manage a voluntary self-exclusion program. ${ }^{61}$ Under section 72 of the CCA 1991:

The Commission or a casino operator may give a written order under this section to a person, on the voluntary application of the person, prohibiting the person from entering or remaining in a casino.

Under section 78, where the casino operator (including its employees) 'reasonably believes that a person the subject of an exclusion order under s 72 is in the casino' it must notify an inspector who must remove the person from the casino. There is no provision directly requiring the casino to have in place

\footnotetext{
${ }^{59}$ Responsible Gambling Codes of Conduct, above n 8, 2-3.

${ }^{60}$ Ibid 19.

${ }^{61}$ Casino Control Act 1991 (Vic), ss 72-78A. See also Casino Control Act 1992 (NSW) ss 7984 and Casino Control Act 1982 (Qld) ss 91N-91P.
} 
procedures for detecting excluded patrons. ${ }^{62}$ By contrast, the Adelaide Casino Responsible Gambling Code of Practice made under the Casino Act 1997 (SA) provides that:

Through the security and surveillance systems operated within and around the licensed premises complex, the licensee will ensure, to the extent reasonably possible, that self barred customers are excluded from the complex.

In Victoria, the consequences of a breach of a self-exclusion order by a problem gambler are governed by section 77 of the CCA 1991. The provision states that if a person, who is subject to an exclusion order, enters or remains in the casino he or she may be liable to a penalty of up to $\$ 2000$. Under section 78B of the CCA 1991, the winnings of a person who is subject to an exclusion order are forfeited to the state. Whether such a fine provides much of a disincentive for problem gamblers to re-enter the venue may be questioned. It is suggested that problem gamblers are people who return to gaming venues despite making heavy losses when gambling. The risk of a penalty may be viewed by such gamblers as merely another risk, akin to a gamble, and for this reason the penalty may have little effect on their behaviour.

\section{The Effectiveness of Self-Exclusion Programs}

There is little data on the effectiveness of gaming venues in removing or excluding gamblers who have entered into a voluntary self-exclusion program. Under the new guidelines proposed by the Victorian Department of Justice in 2008:

A self-exclusion program must set out a process by which the venue operator will assess the operation and effectiveness of the program and must specify:

(a) how often the self-exclusion program will be reviewed;

(b) the criteria that will be used to assess the effectiveness of the selfexclusion program;

${ }^{62}$ Cf Adelaide Casino Responsible Gambling Code of Practice cl 6, made under the Casino Act 1997 (SA) which provides that:

Through the security and surveillance systems operated within and around the licensed premises complex, the licensee will ensure, to the extent reasonably possible, that self barred customers are excluded from the complex. 
(c) how customers who have self-excluded and problem gambling support services can have input into the review process;

(d) who will be provided with a copy of the review findings. ${ }^{63}$

As yet, these guidelines have not resulted in the publication of any data on the effectiveness of self-exclusion programs.

The South Australian Centre for Economic Studies (the 'SACES') in its 2003 report titled Evaluation of Self-exclusion Programs and Harm Minimisation Measures: Report A suggests that there may be instances where the gaming venue has not actually implemented a consistent system for ensuring that selfexcluded gamblers can be detected, removed from the venue and/or precluded from further entering. ${ }^{64}$ Further, the SACES found that, even where a gaming venue may have a detecting system implemented to identify self-excluded patrons, such a system may be weak and problem gamblers are nevertheless circumventing them. ${ }^{65}$ It appears that many gaming venues rely on a 'facial recognition system'. Given the high number of patrons, whether such a system will actually identify problem gamblers on a regular basis is questionable.

The suggestion in the SACES report - that self-exclusion programs may be minimally effective - is supported by evidence derived from case law. The decision of Kakavas $v$ Crown $\operatorname{Ltd}^{66}$ demonstrates an extreme example of disregard by a casino for the decision of a problem gambler to self-exclude. In this case the plaintiff alleged that, even though he applied for self-exclusion, the gaming venue 'concocted a scheme to lure the plaintiff back to the Casino'. ${ }^{67}$ Indeed, the plaintiff alleged that '[i]nstructions were accordingly given to Crown employees "to do whatever was necessary to induce the plaintiff to return and recommence gambling.", 68 The measures adopted to ensure that the plaintiff would return and recommence gambling included approaches from employees of the Casino 'who offered the plaintiff

\footnotetext{
${ }^{63}$ Business Victoria, Government of Victoria, Gaming Venue Business Toolkit: Responsible Gambling, Chapter 14 (2008) 16. Also at <http://www.business.vic.gov.au /busvicwr/_assets/main/lib60180/sbv+toolkit+ch14.pdf>.

${ }^{64}$ Evaluation of Self-exclusion Programs, above n 8, 19.

${ }^{65}$ Ibid.

${ }^{66}$ [2007] VSC 526 (8 December 2009).

${ }^{67}$ Ibid [16].

${ }^{68}$ Ibid.
} 
inducements, such as permission to bet up to \$3 000000 per hand, and a 20\% rebate on losses' ${ }^{69}$

Foroughi $v$ Star City Pty Limited ${ }^{70}$ ('Foroughi') also illustrates the flaws inherent in some of the systems in place in gaming venues for detecting selfexcluded gamblers. The plaintiff, Mr Foroughi, gave evidence that within a few weeks of making a voluntary self-exclusion order:

I went back to the Casino to see whether the Exclusion Order would work and whether the Casino staff would stop me from going back into the premises. I was very scared that the Casino staff would catch me. But nobody noticed me and I was not caught so I returned a few more times. ${ }^{71}$

Between 11 June 2004 and 28 January 2006, Mr Foroughi entered the Star City, a casino in New South Wales, on 65 occasions, incurring losses ranging from $\$ 1000$ to $\$ 73000$. Mr Foroughi continued to enter the casino even after initiating an action against the venue:

On 23 November 2005, Ms Virginia Baker, who holds the position of Responsible Gambling Manager for Star City, sent a memo to the Casino's Security Managers and Surveillance Managers about Mr Foroughi's claims. She requested that Mr Foroughi's photograph be placed on a 'persons of interest' board, also known as the 'hot list', to assist staff to prevent him from entering the casino.

In spite of the hot list posting, Mr Foroughi's unchallenged evidence is that he entered the casino on 16 December 2005 and gambled large amount of money on the roulette tables. Indeed, so large was his betting that he claims he was offered the facilities of 'the high rollers" room. He claims to have suffered losses totalling $\$ 100,000$ on 16 December 2005 and 17 December $2005 .^{72}$

The defendant, Star City, gave evidence as to the number of exclusion orders issued:

In 2003/2004, 490 exclusion orders were issued by Star City, of which 186 were voluntary exclusion orders. In 2004/2005, Star City issued 504 exclusion orders, of which 163 were voluntary exclusion orders.

\footnotetext{
${ }^{69}$ Ibid.

${ }^{70}$ [2007] FCA 1503 (27 September 2007).

${ }^{71}$ Ibid [15].

${ }^{72}$ Ibid [20]-[21].
} 
In 2004/2005, Star City had in place approximately 4,000 current exclusion orders, of which over 1,000 were voluntary exclusion orders. ${ }^{73}$

The process of exclusion involved facial recognition by staff:

Surveillance operators are required to familiarise themselves with photographs of excluded patrons on the database. In addition, the Security Department maintains a register of excluded patrons, with approximately 200 lever arch folders of documentation relating to excluded patrons. ${ }^{74}$

Star City further provided figures as to its success in detecting excluded patrons as follows: ${ }^{75}$

\begin{tabular}{|l|l|l|}
\hline Year & $\begin{array}{l}\text { Number of self-excluded } \\
\text { patrons detected }\end{array}$ & Number of occasions \\
\hline $2002 / 2003$ & 245 & 305 \\
\hline $2003 / 2004$ & 206 & 247 \\
\hline $2004 / 2005$ & 202 & 246 \\
\hline
\end{tabular}

Star City accepted that 'it was possible for excluded patrons to re-enter the casino' because memorising every excluded person's face was not possible. ${ }^{76}$ It may be suggested that the proportion of excluded patrons who attempt to reenter the casino, or the success of Star City in detecting them, is difficult to assess without knowing the total number of valid voluntary self-exclusion orders in effect. Nevertheless, the number of self-excluded patrons detected entering the casino in 2003/4 and 2004/5 was higher than the number of orders issued in those years.

By contrast, overseas experience indicates that the use of a smart card technology system is possibly the most efficient mechanism for the identification of self-excluded patrons. ${ }^{77}$

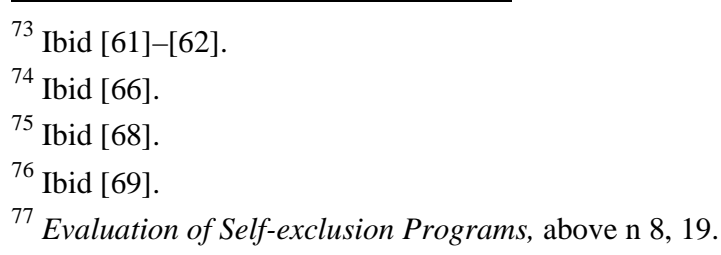




\section{A Smart Card System}

A smart card is a plastic card that is similar to the standard bank or credit card. It is capable of storing data relevant to the person to whom the card has been issued. By containing an embedded microprocessor, the card ensures that only an authorised card reader is capable of reading the data stored on the card. ${ }^{78}$ This means that, although personal sensitive information may be stored on the card, that information is protected.

Such cards may be used in a beneficial manner in the context of exclusion orders, as they identify gambling patrons via a photograph or a stored digital image. The advantage of including an identifying image is that it may be displayed electronically when a patron is using an EGM. This would facilitate the conducting of passive checks by the gaming venue in order to ensure that patrons who are using EGMs are using their personal card, and, more importantly, that they are permitted to access the gaming area. Alternatively, gaming patrons could be required to either swipe their card or insert it into a machine before being granted access to a gaming area. This would provide a method by which gaming venues could successfully prevent excluded patrons from entering gaming areas. For example, in the Netherlands, personal identification of individuals is required before they can enter any one of the twelve casinos. A computer is able to immediately identify self-excluded patrons, and a computerised monitoring system across venues facilitates the identification of a self-excluded patron who is trying to enter more than one gambling venue. ${ }^{79}$

Further, a smart card can be programmed to identify problem gamblers. The card has the ability to store data, including patterns of gaming activity. Such data, coupled with expert research, has the potential to identify problem gamblers. Where appropriate, such gamblers may be temporarily suspended to prevent further gambling harm.

The introduction of a smart card system into gaming venues would not require much development. For example, in Victoria, all three major gaming corporations have various forms of card-based loyalty programs. ${ }^{80}$ When visiting a gaming venue, patrons can insert their card into a card reader for the

\footnotetext{
${ }^{78}$ See HowStuffWorks Inc, What is a "smart card"? (1 April 2000) HowStuffWorks.com $<$ http://computer.howstuffworks.com/question332.htm>.

${ }^{79}$ Evaluation of Self-exclusion Programs, above n 820.

${ }^{80}$ The loyalty programs include: Tabaret Rewards, Tatts Pokies Advantage and Crown Club. See Gambler's Help Southern, 'Smart Cards: The Overdue Magic Bullet?' (GM Newsletter, No 4(8), Gambler’s Help Southern, February 2006) 1.
} 
purpose of receiving reward points. Gaming patrons may then exchange these reward points for benefits such as food and drink. The current loyalty program is, however, flawed as a control mechanism primarily because is an opt-in program rather than making patron-identification a prerequisite for entering a gaming venue. Further, a gaming patron must currently possess separate loyalty cards for each venue, rather than a single card. Nevertheless, the operation of these loyalty programs does not differ significantly from the operation of a smart card system.

In this context, it is worth noting that in 2005, South Australia's Independent Gambling Authority (SAIGA) conducted extensive research into smart card technology. ${ }^{81}$ SAIGA published a report that, although it did not call for a mandatory smart card system, made recommendations that a system be implemented that allows for: (a) playtime to be systematically tracked; (b) players to set limits on their play; and (c) players to be excluded either voluntarily, or by the gaming venue, or under relevant family law provisions. ${ }^{82}$

\section{Legal Accountability of a Gaming Venue that FAILS to DETECT AND EXCLUde A PROBLEM GAMBLER}

According to the website of the Australian Hotels Association:

Self-exclusion is an entirely voluntary process. It is an agreement the individual makes with themselves, for themselves. It involves no other person in any responsibilities - legal or otherwise. ${ }^{83}$

It is suggested that there is some legal responsibility imposed on a gaming venue that conducts a voluntary self-exclusion program. However, the opportunities for legal redress for a problem gambler who has entered into a voluntary self-exclusion program and has failed to be excluded by the gaming venue in question are limited.

\footnotetext{
81 Independent Gambling Authority (SA), Inquiry into Smartcard Technology (Report, Independent Gambling Authority, 2005) <http://www.iga.sa.gov.au/pubcons/ smartcrd/SCTInqRep-final-web.pdf $>$.

${ }^{82}$ Ibid 42.

${ }^{83}$ Self-exclusion, above n 9.
} 


\section{A Breach of Statutory Duty}

As noted above, certain legislation regulating the gaming industry imposes an obligation on the gaming venue to facilitate a voluntary self-exclusion program. Where a gaming venue fails to effectively exclude a gambler, the possibility of an action for breach of statutory duty arises. The imposition of liability for breach of statutory duty is dependent on whether the legislation

which imposes an obligation for the protection or benefit of a particular class of persons is, upon its proper construction, intended to provide a ground of civil liability when the breach of the obligation causes injury or damage of a kind against which the statute was designed to afford protection. ${ }^{84}$

Courts have generally been unwilling to recognise a claim for a breach of statutory duty in the context of the gaming industry in favour of the problem gambler. In Reynolds v Katoomba RSL All Services Club Ltd ${ }^{85}$ ('Reynolds') the plaintiff's claim for breach of statutory duty arising from the Registered Club Act 1976 (NSW) was dismissed at first instance on the basis that the Act did not expressly endow the plaintiff with a private right of action, nor was there a legislative intention to confer such a right. ${ }^{86}$

In Preston v Star City Pty Ltd ${ }^{87}$ ('Preston') the plaintiff alleged, inter alia, a breach of statutory duty by the Casino when it allowed him to gamble whilst intoxicated. According to the plaintiff, in doing so, the defendant Casino breached section 163 of the Casino Control Act 1992 (NSW), which prohibits intoxicated people from gambling at a casino. In an action by the Casino to strike out the plaintiff's statement of claim, Wood CJ found that, in the context of the comprehensive regulatory scheme enacted by the Casino Control Act 1992 (NSW), which includes disciplinary actions in the event of contraventions of the regulations, the legislative intention required to facilitate private rights of action for damages was lacking. ${ }^{88}$ Wood CJ also held that:

\footnotetext{
${ }^{84}$ Byrne v Australian Airlines Ltd (1995) 185 CLR 410, 424 (Brennan CJ and Dawson and Toohey JJ).

85 [2001] NSWCA 234 (20 September 2001).

${ }^{86}$ Ibid (Spigelman CJ, Powell and Giles JJA).

${ }^{87}$ [1999] NSWSC 1273 (1 February 2000).

${ }^{88}$ Ibid [87].
} 
There is nothing in [the Street Report or the Second Reading Speech], or in the Act itself, to suggest that there should be a private right of action additional to the obligations imposed upon casino operators. ${ }^{89}$

The claim for breach of statutory duty was struck out for the reason that it would not be supported in law.

In Foroughi ${ }^{90}$ the claim for breach of statutory duty under section 85 of the Casino Control Act 1992 (NSW) was not argued at the hearing. Jacobson J also held:

In any event, the legislative history and the case law indicate that the intention of the Casino Control Act was not to confer a private right of action for damages on problem gamblers who may enter a casino in breach of an exclusion order. ${ }^{91}$

\section{B Contract}

Typically, a gambler entering into a voluntary self-exclusion program will sign some form of document recording the arrangement. The document may vary between venues. One form of voluntary self-exclusion document is a 'Deed of Self-exclusion' ('Deed') found on the 'Australian Hotels Association/Licensed Clubs Association of Victoria' website. ${ }^{92}$ The Deed states that it is to be executed as a deed poll, that is, an obligation imposed on one party only. The Deed provides that the problem gambler undertakes not to enter the gaming area of designated gaming venues, and not to use gaming machines at the nominated venues. ${ }^{93}$ In addition, the problem gambler undertakes to seek, and continue to seek, the assistance and advice of a problem gambling counsellor. ${ }^{94}$ The problem gambler authorises management of a nominated venue to take all actions as deemed necessary by us (including the use of reasonable force) to have you removed and prevent you from further access' ${ }^{95}$ The problem gambler generally nominates a period of exclusion, which may be somewhere between a minimum of six months and a

\footnotetext{
${ }^{89}$ Ibid.

${ }^{90}$ [2007] FCA 1503 (27 September 2007).

${ }^{91}$ Ibid [95] (Jacobson J).

${ }^{92}$ For an example of a Deed of Self-exclusion see Australia Hotels Association, SEGO Sample Deed, (2008) Australia Hotels Association < http://www.ahavic.com.au/deed/index.html>.

${ }^{93}$ Ibid cl 2.

${ }^{94}$ Ibid cl 8.

${ }^{95}$ Ibid cl 3.
} 
maximum of two years. ${ }^{96}$ A breach of a Deed raises no express liability for either the problem gambler or the gaming venue. The document is drafted to ensure that no obligation is placed on the gaming venue. It expressly provides 'I understand that Self-exclusion from Restricted Gaming Areas at the Venue/s is made voluntarily and does not place any obligation, duty or responsibility on anyone except myself ${ }^{.97}$

In the absence of any obligation on the gaming venue, the Deed cannot operate as a contract. If the document did contain mutual undertakings, it might be argued to operate as a contract. Nevertheless, it appears that there may be attempts by the gaming venue to limit its liability for breach of contract or indeed other causes of action. For example, the Deed cited above, contains an indemnity clause (cl 17) stating that the gaming venue is to be exempt from all

actions, liabilities, proceedings, losses, claims, damages, costs and expenses which the Indemnified Persons may suffer, incur, or sustain in connection with or arising directly or indirectly from any act, default or omission.

However, it is suggested that the mere inclusion of a 'reverse indemnity' clause may not exempt the gaming venue from potential liabilities. The clause may be void as illusory. If the core undertaking of the gaming corporation is to prevent the problem gambler from remaining on the premises it is difficult to see how a clause that excludes all responsibility leaves any content to the core obligation. Further, it has been held that, in circumstances where a 'reverse indemnity' attempts to defeat the effect of a statutory right, such as that found under section 52 of the TPA, it is unlikely to be effective. ${ }^{98}$

If the Deed used by a gaming venue did in fact operate as a contract, then a failure to exclude a patron who has entered into such a contract would be evidence of a breach on the part of the gaming venue. However, the problem gambler would also be in breach of the contract. This raises the question of whether the wrongdoing on the part of the problem gambler precludes him or her from an action for breach of contract. In Foroughi the voluntary selfexclusion order was made on a form of application signed by the gambler and witnessed by an employee of Star City. The gambler stated in the application that 'he recognised that it was his responsibility not to enter the gaming areas

\footnotetext{
${ }^{96}$ Ibid cl 7.

${ }^{97}$ Ibid.

98 See Petera Pty Ltd v EAJ Pty Ltd (1984) 7 FCR 375; Byers v Dorotea Pty Ltd (1986) 69 ALR 715, 725; Clark Equipment Australia Ltd v Covoat Pty Ltd (1987) 71 ALR 367.
} 
and he undertook not to do so'. He also undertook to seek assistance and advice from a qualified counsellor in problem gaming. ${ }^{99}$ Jacobson $\mathrm{J}$ held that:

Mr Foroughi breached the terms of his undertakings set out in the application for an exclusion order. Even if there were a term of the contract under which Star City agreed to take reasonable steps to apprehend and remove Mr Foroughi, I do not consider that Star City was in breach of it.

Any loss suffered by Mr Foroughi was caused, not by Star City, but by $\mathrm{Mr}$ Foroughi's deliberate and voluntary conduct in entering the casino and gambling in breach of his written undertakings. ${ }^{100}$

This conclusion may be questioned. The deed was entered into for the reason that the problem-gambler lacked self-control in respect to gambling and therefore needed the assistance of the gaming venue to help control the problem. ${ }^{101}$ If the gaming venue is to be absolved from any liability - in particular in circumstances where a problem gambler engages in behaviour for which it has sought assistance - then the self-exclusion agreement is rendered ineffective. A problem gambler who enters into such a program has taken steps to address his or her difficulty with gambling. However, the selfexclusion program may not be enough to curtail the addiction. Such a person is 'under a disability"102 and may therefore be unable to ensure that he or she does not re-enter the gaming venue in question. Arguably, in entering such a program, the problem gambler assumes that the gaming venue will do everything reasonably within its power, as promised. If a gaming venue is not to be held liable after it has entered into such programs, there appears to be no incentive for the gaming venue to ensure that such programs are governed effectively.

\section{Negligence}

Courts have generally held that a gaming venue does not owe a duty of care to a person in circumstances where it knew, or ought to have known, that the person was a problem gambler to protect that person against financial loss from gambling. ${ }^{103}$ In Reynolds, the plaintiff $\mathrm{Mr}$ Reynolds first became

\footnotetext{
${ }^{99}$ Foroughi [2007] FCA 1503 (27 September 2007), [3].

${ }^{100}$ Ibid [143]-[144].

${ }^{101}$ Evaluation of Self-exclusion Programs, above n 8, 47.

${ }^{102}$ Kakavas v Crown Melbourne Ltd [2009] VSC 559 (8 December 2009), [440]-[444].

${ }^{103}$ Reynolds [2001] NSWCA 234 (20 September 2001) (Spigelman CJ, Powell and Giles JJA); Foroughi [2007] FCA 1503 (27 September 2007); Politarhis v Westpac Banking Corporation [2008] SASC 296 (31 October 2008).
} 
familiar with poker machines, and other forms of gambling in 1984 at the age of 19, when he commenced employment at the Katoomba Golf Club. By 1991, he was going to the Club to gamble every day. At first, he would lose around $\$ 100$, but his losses became progressively higher. ${ }^{104}$ By 1994 , he had gambled away in excess of $\$ 250$ 000. The Club was aware that Mr Reynolds had a problem with gambling but continued to facilitate his gambling addiction by cashing his personal, business and third party cheques, despite being asked by both Mr Reynolds and his family to desist from doing so. For such reasons, Mr Reynolds argued that the Club breached its duty of care to him and acted unconscionably in its dealings with him. At first instance, the trial judge held that, although Mr Reynolds was a 'compulsive gambler' and the Club was aware of this, the act of gambling was, in the end, a question of Mr Reynolds' free will. Mr Reynolds then appealed to the New South Wales Court of Appeal where Spigelman CJ stated:

In my opinion the law should not recognise a duty of care to protect persons from economic loss, where the loss only occurs following a deliberate and voluntary act on the part of the person to be protected. There may be, however, an extraordinary case where a duty should be recognised. The present case is not such. ${ }^{105}$

Chief Justice Spigelman emphasised that mechanisms other than reliance on the gaming venue were available to the plaintiff to control his gambling:

It may well be that the Appellant found it difficult, even impossible, to control his urge to continue gambling beyond the point of prudence. However, there was nothing which prevented him staying away from the club. The suggested duty on the club to advise him to resign his membership emphasises the point. He could have resigned at any time. The requests to refuse to cash cheques when asked, did not shift his personal responsibility for his own actions to the club. There was no reason for the club to honour one request rather than the other. ${ }^{106}$

This approach was followed in Foroughi, where Jacobson J stated that the responsibility to control the plaintiff's gambling lay with the plaintiff not the casino. ${ }^{107}$

\footnotetext{
${ }^{104}$ Reynolds [2001] NSWCA 234 (20 September 2001), [58].

105 Ibid [17], [27].

${ }^{106}$ Ibid [48].

${ }^{107}$ Foroughi [2007] FCA 1503 (27 September 2007), [128].
} 
It may be argued that the approach indicated in these cases should not apply in cases where a problem gambler has entered into a voluntary self-exclusion agreement. Here, the circumstances differ from the normal case of a problem gambler. Where a gambler has entered into a voluntary self-exclusion program, the individual has taken some responsibility for his or her problem gambling by seeking to be banned from the gaming venue. The gaming venue has also accepted some element of responsibility through its operation of the program. However, even if a gaming venue prima facie owes a duty of care to a gambler who has entered into a voluntary self-exclusion program, the mere entry of the gambler into the venue will not necessarily breach that duty. The duty is one of reasonable care. The gambler would need to show something more, such as a failure by the gaming venue to put in place a reasonable program or a lack of reasonable care in implementing that program.

In Preston v Star City Pty Ltd (No 3), ${ }^{108}$ ('Preston No (3)') Hoeben J allowed a claim in negligence, and a claim for a breach of statutory duty, to continue to trial because the allegations went beyond those made in Reynolds. The case concerned the plaintiff, Preston, who alleged that he suffered losses of approximately \$3 million as a result of gambling at Star City, a casino in New South Wales ${ }^{109}$ Preston argued that Star City was aware of his problem with gambling and that it proactively encouraged the gambling by enticing him with promises that 'if he remained a high roller patron it would make available various business contracts related to its procurement needs or promotions'. Further, Preston alleged that Star City took advantage of his gambling weakness by providing a cheque-cashing facility and certain benefits, including free alcohol.

On appeal at first instance, Wood CJ held that, on the facts, a duty of care may not 'go so far as preventing the offer of a limited or reasonable range of inducements and complimentary services'. ${ }^{110}$ Notwithstanding this, his Honour further held that a duty of care may exist to discourage

the provision of significant credit facilities or excessive encouragement through incentives, of a person who has specifically asked to be barred or to go beyond a limit that he has asked the casino to set. ${ }^{111}$

In permitting the claim for negligence, Wood CJ held that the Court should be 'astute not to risk stifling the development of the law'. ${ }^{112}$ Further, his Honour

\footnotetext{
108 [2005] NSWSC 1223 (5 December 2005) ('Preston No (3)’).

${ }^{109}$ Preston v Star City Pty Ltd [1999] NSWSC 459 (18 May 1999) [3].

${ }^{110}$ Preston v Star City Pty Ltd [1999] NSWSC 1273 (1 February 2000) [132].

111 Ibid [133].
} 
held that the developing nature of the tort of negligence, and 'the incremental approach ... make it inappropriate to [strike out the common law count] ... merely because no category of case of this kind has been recognised in this country'. ${ }^{113}$ On a further application hearing, Hoeben $\mathrm{J}$ held that a duty of care might be breached so as to give rise to a cause of action in negligence, where the defendant operator of a gambling establishment, knowing that a patron was a 'problem gambler', carelessly failed to ensure that its employees did not exploit that patron's weakness. ${ }^{114}$

By contrast, in Foroughi, ${ }^{115}$ Jacobson J considered that the casino's use of only a facial recognition system for identifying self-excluded gamblers was not a breach of any duty of care by the casino to such gamblers. In Foroughi ${ }^{116}$ the plaintiff, Mr Foroughi, who described himself as both a 'problem gambler' and 'pathological gambler', applied for a voluntary exclusion order pursuant to section 79(3) of the Casino Control Act 1992 (NSW), after having suffered substantial gambling losses. Star City, the defendant, made such an order against Mr Foroughi on 18 May 2004. Notwithstanding the operation of the exclusion order, Mr Foroughi alleged that he entered Star City's casino on 65 occasions and as a result, suffered gambling losses amounting to many hundred of thousands of dollars. ${ }^{117} \mathrm{Mr}$ Foroughi therefore sought to recover those losses from Star City, asserting that the defendant owed him a duty of care to, inter alia, 'take reasonable steps to prevent him from entering the gaming areas of the casino and/or to remove him from the casino' ${ }^{118}$ In addition, Mr Foroughi sought to sue for damages pursuant to sections 52 and 92 of the Trade Practices Act 1974 (Cth) because of representations that were made by an employee of Star City. The representations made to Mr Foroughi were to the effect that (a) Star City had approximately 5000 surveillance cameras which could be used to detect $\mathrm{Mr}$ Foroughi if he were to enter Star City and that (b) as soon as Star City became aware of Mr Foroughi's presence in the casino, Star City would remove him from the premises. ${ }^{119}$

\footnotetext{
${ }^{112}$ Preston v Star City Pty Ltd [1999] NSWSC 459 (18 May 1999), [42].

${ }^{113}$ Preston v Star City Pty Ltd [1999] NSWSC 1273 (1 February 2000) [118].

${ }^{114}$ Preston (No 3) [2005] NSWSC 1223 (5 December 2005), [55]. See also Kakavas v Crown

Ltd [2007] VSC 526 (8 December 2009), [46] (Harper J).

115 [2007] FCA 1503 (27 September 2007).

116 Ibid.

${ }^{117}$ Ibid [4].

${ }^{118}$ Ibid [6].

${ }^{119}$ Ibid [7].
} 
In considering Mr Foroughi's claims, Jacobson $\mathrm{J}$ held that the possibility that the casino might use more sophisticated technology to detect excluded patrons was a matter for the regulatory authority, not the courts. ${ }^{120}$ It appears that most venues use facial recognition schemes as a means of identifying problem gamblers excluded from the venue. For example, as discussed earlier, in Star City, surveillance operators are asked to familiarise themselves with photographs of excluded patrons, recognise them on surveillance tapes and consequently to remove them from the premises. ${ }^{121}$ As Jacobson J held, 'some staff are particularly good at recognising and detecting excluded patrons whereas others are not as good at this task'. ${ }^{122}$

On the basis of industry practice, it would appear that merely relying on such schemes does not breach any duty of care owed by a venue to a self-excluded patron. However, it also appears that these systems, at the very best, work only poorly. It might accordingly be argued that the standard of reasonable care should require more from venues. For example, the standard could be to require the gaming venue to use the smart card technology system, as discussed above.

\section{Misleading and Deceptive Conduct}

Conduct that is misleading and deceptive is prohibited under the TPA, as well as by state and territory legislation. ${ }^{123}$ There are a number of possible ways in which a claim of misleading and deceptive conduct may be raised against a gaming venue in relation to a voluntary self-exclusion program. One possible claim may arise if the employees of a gaming venue, or the documentation associated with the voluntary self-exclusion program, exaggerate the effectiveness of the gaming venue in detecting and removing excluded patrons. As discussed, in Foroughi ${ }^{124}$ the plaintiff entered into a voluntary self-exclusion agreement with the defendant, Star City, and then proceeded to enter the defendant casino, suffering gambling losses to the amount of hundreds of thousands of dollars. ${ }^{125}$ Foroughi alleged that representations were made to him by an employee of Star City in relation to the effectiveness

\footnotetext{
120 Ibid [138].

121 Ibid [44], [69].

122 Ibid [64].

${ }^{123}$ See eg, Fair Trading Act 1999 (Vic); Fair Trading Act 1992 (ACT); Fair Trading Act 1989 (Qld); Fair Trading Act 1987 (NSW).

124 [2007] FCA 1503 (27 September 2007).

${ }^{125}$ Ibid [4].
} 
of the voluntary self-exclusion agreement. These representations were to the effect that:

Star City had 5,000 surveillance cameras in the casino which would be able to detect Mr Foroughi if he entered the gaming areas; and as soon as practicable after it became known to Star City ... Star City would remove him from the premises. ${ }^{126}$

The representations also included the statement that '[w]e have got a system that no-one can escape from the system, so even if you come, we will catch you'. 127

The trial judge rejected the plaintiff's evidence, holding that the statements in question were not made. This finding was largely based on the view that an employee would not have made inaccurate statements. ${ }^{128}$ It is suggested, however, that a plaintiff is equally unlikely to have imagined a statement given in this detail in the absence of a representation made by a member of staff.

An appeal by the plaintiff was dismissed ${ }^{129}$ on the basis that, even if the alleged statements had been made, ${ }^{130}$ the plaintiff placed no reliance on any representation he claimed had been made to him. ${ }^{131}$ This approach negates entirely the role of any representations made by the gaming venue. If the only way the plaintiff could show reliance on the representations were by not returning to the venue, then the veracity of those representations could never be tested. Another explanation given by the court was that the plaintiff's very problem was his inability to control his urges to gamble. The plaintiff accordingly entered into a voluntary self-exclusion program to assist him in controlling his compulsion. On the basis of the representations by the gaming venue's employees, the plaintiff expected to be excluded, should he be compelled to return. The plaintiff therefore did not take further steps to control his gambling compulsion.

Jacobson J held that, had the statement been made and relied on, there would have been no reasonable grounds upon which the statement could be made, as

\footnotetext{
${ }^{126}$ Ibid [7].

${ }^{127}$ Ibid [32].

${ }^{128}$ Ibid [87]-[90].

${ }^{129}$ Ibid [150].

${ }^{130}$ Ibid [85]-[86].

131 Ibid [85].
} 
Star City was unable to adequately identify the plaintiff if he entered the casino:

Star City's evidence of the systems it had in place to detect excluded patrons and its evidence of the size of the casino and volume of patronage, shows that there was no guarantee that excluded patrons would be detected. $\mathrm{Mr}$ Clark accepted that this was so. ${ }^{132}$

Jacobson $\mathrm{J}$ further held that the casino had $\mathrm{no}^{133}$ reasonable grounds for making statements to the effect that Star City would remove the plaintiff from the casino as soon as practicable after it knew that he was present. ${ }^{134}$ Thus, it appears that Jacobson $\mathrm{J}$ recognised the inadequacies of the system in place at the gaming venue. In these circumstances, it might be argued that the very act of promoting the existence of a self-exclusion program was misleading.

\section{E Unconscionable Conduct}

A problem gambler who has entered into a voluntary self-exclusion program which has proved to be ineffective might be able to claim that the gaming venue has engaged in unconscionable conduct contrary to the provisions of the TPA and other state based legislation. ${ }^{135}$ Part IVA of the TPA deals with unconscionable conduct in trade or commerce, and under section 51AB:

A corporation shall not, in trade or commerce, in connection with the supply or possible supply of goods or services to a person, engage in conduct that is, in all the circumstances, unconscionable.

The limitation of the prohibition in section $51 \mathrm{AB}$ to consumer transactions is effected by sub-sections (5) and (6). Sub-section (5) states that 'goods or services' refers to 'goods or services of a kind ordinarily acquired for personal, domestic, or household use or consumption'. Gambling services would fall within this definition.

In considering whether conduct is unconscionable under the TPA, courts may have regard to decisions on unconscionable dealing in equity. In particular, in

\footnotetext{
132 Ibid [88].

133 Ibid [87]-[90].

${ }^{134}$ Ibid [90].

135 See Fair Trading Act 1999 (Vic); Fair Trading Act 1992 (ACT); Fair Trading Act 1989 (Qld); Fair Trading Act 1987 (NSW).
} 
the landmark case of Commercial Bank of Australia v Amadio, ${ }^{136}$ Deane $\mathrm{J}$ held that the doctrine applied where:

1. a party to a transaction was under a special disability in dealing with the other party with the consequence that there was an absence of any reasonable degree of equality between them; and

2. the disability was sufficiently evident to the stronger party to make it prima facie unfair or 'unconscientious' that he procure, or accept, the weaker party's assent to the impugned transaction in the circumstances in which he procured or accepted it.

3. Where such circumstances are shown to have existed, an onus is cast upon the stronger party to show that the transaction was fair, just and reasonable. ${ }^{137}$

\section{$1 \quad$ Special Disability}

The circumstances which will give rise to a special disability are not defined at common law and the categories are not closed. Fullagar J's statement in Blomley $v$ Ryan ${ }^{138}$ provides insight into the types of circumstances which may be relevant for the purposes of establishing a special disability:

$[\mathrm{P}]$ overty, or need of any kind, sickness, age, sex, infirmity of body or mind, drunkenness, illiteracy, or lack of education, lack of assistance or explanation where assistance or explanation is necessary. The common characteristic seems to be that they have the effect of placing one party at a serious disadvantage vis-à-vis the other. ${ }^{139}$

A problem gambler might be described as acting under a special disability in relation to the gaming venue. As previously discussed, a 'problem gambler' is someone who begins to exhibit frequent, uncontrolled gambling behaviour which leads to subsequent harm. ${ }^{140}$

In the decision of Paradise Enterprises Inc $v$ Kakavas ${ }^{141}$ Harper J accepted that in circumstances where a person is a pathological gambler he or she 'may have an ... an impaired ability to control the frequency of gambling and the

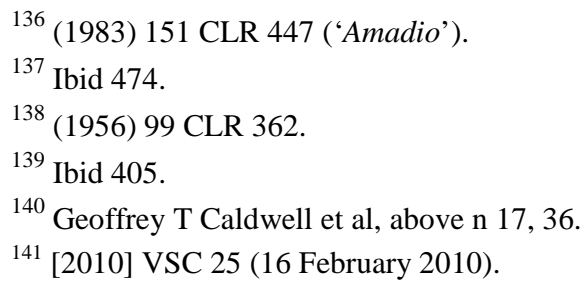


amount of money wagered. That is to say ... the condition is capable of characterisation as a special disability for the purposes of the doctrine of unconscionable dealing. ${ }^{142}$

In Foroughi ${ }^{143}$ the plaintiff called evidence from a clinical psychologist who concluded that Foroughi satisfied the criteria stipulated in the DSM IV for a 'pathological' gambler. ${ }^{144}$ The psychologist further stated that neuro-scientific evidence indicates that:

Over time, pathological gamblers suffer from long lasting structural changes to the brain with reduced capacity to make rational decisions to cease gambling.

Expert evidence for the respondent maintained that Foroughi, despite demonstrating five of the ten criteria set out by the DSM IV, could only be labelled as a 'problem gambler'. Jacobson $\mathrm{J}$ accepted this evidence and concluded in his judgment that the plaintiff was a problem and not pathological gambler. His Honour concluded that the plaintiff was not suffering under any special disability. ${ }^{145}$

Notwithstanding the distinction made by Jacobson $\mathrm{J}$ in Foroughi, it is proposed that the fact that an individual is a problem gambler should be sufficient for the purpose of establishing a 'special disability'. As discussed previously, the term 'pathological gambler' is not necessarily reflective of the Australian approach to considering the difficult issues stemming from EGM gambling. In Preston ${ }^{146}$ Wood CJ adopted a 'problem gaming' classification. The case involved the plaintiff, Preston, bringing several causes of action, including one for unconscionable conduct, against Star City Pty Ltd. Preston alleged, inter alia, that Star City was aware of his problem with gambling and induced him to take part in gaming in the casinos by assuring him that 'if he remained a high roller patron it would make available various business contracts related to its procurement needs or promotions'. ${ }^{147}$ The plaintiff claimed that he was the weaker party as he was a 'problem gambler' with an addiction to that activity. ${ }^{148}$ In rejecting an action to strike out the claim by the Casino, Wood CJ held that the plaintiff's position as a problem gambler

\footnotetext{
142 Ibid [12] (Harper J).

143 [2007] FCA 1503 (27 September 2007).

144 Ibid [105].

145 Ibid [140].

146 [1999] NSWSC 1273 (1 February 2000).

${ }^{147}$ Ibid [13].

${ }^{148}$ Ibid [177].
} 
'could be equated to that of a person with a mental weakness, which was there for the exploitation'. 149

Similarly, in the case of American Express International $v$ Simon Famularo, ${ }^{150}$ Naughton $\mathrm{J}$ held that a person who is a pathological or problem gambler has a special disability. The case concerned the plaintiff, Famularo, bringing a claim of unconscionable conduct against a hotel whose staff made representations to Famularo that he could get a cash advance against his credit card so that he could gamble at the hotel. This induced the plaintiff to stay and gamble on the premises. ${ }^{151}$ Consequently, Naughton J held that the hotel's conduct of taking advantage of Famularo was unconscionable and the pertinent 'special disadvantage' was the plaintiff's pathological gambling in conjunction with his inability to know that the cash advances that the hotel allowed for were illegal and breached the Liquor Act 1982 as well as the merchant agreement between Amex and the hotel. ${ }^{152}$ Further, the Court held that, had Famularo been informed by the hotel staff, that he could not obtain cash advances, he would have accepted this fact and his transactions with American Express would not have occurred. Naughton J said, 'the ease with which the defendant was permitted by the hotel to get cash advances from it against his American Express card increased the frequency of the defendant's gambling and the amounts of money which he used for it. I find that the said misrepresentations were untrue and amounted to misleading conduct., ${ }^{153}$ For such reasons, the Court held that the hotel's conduct in misrepresenting to the defendant that he could obtain cash advances, and in fact making those advances, was 'in all the circumstances of this case unconscionable within the meaning of s 51AB of the Trade Practices Act 1974 (Cth)'. ${ }^{154}$

\section{$2 \quad$ Knowledge of the Disability}

The second element of the doctrine of unconscionable conduct is that:

the disability was sufficiently evident to the stronger party to make it prima facie unfair or 'unconscientious' that he procure, or accept, the weaker

\footnotetext{
${ }^{149}$ Ibid [178].

150 (Unreported, Limited District Court of NSW, Naughton DCJ, 19 February 2001).

151 Ibid 21.

152 Ibid.

153 Ibid.

${ }^{154}$ Ibid 41.
} 
party's assent to the impugned transaction in the circumstances in which he procured or accepted it. ${ }^{155}$

This requirement may be referred to as one of knowledge. It is only when the stronger party proceeds with the transaction in light of the knowledge of the weaker party's special disability that the victimisation of the weaker party occurs. ${ }^{156}$ There are several ways in which the stronger party may satisfy this element. Most obviously, the element would be satisfied through the actual knowledge of the weaker party's special disability. However, in the case of Amadio, Deane and Mason JJ held that 'wilful ignorance is not to be distinguished in its equitable consequences from knowledge'. Thus, wilful ignorance (where the stronger does not turn his or her mind to the weaker party's vulnerability) is also sufficient for the purpose of making out the knowledge element. It should also be noted that in the case of Amadio no 'actual knowledge' was possessed by the defendants. The majority did, however, make a statement that the special disability of the Amadios would have been evident to any reasonable person. Thus, it may be inferred that, in circumstances where the plaintiff cannot necessarily make out either actual knowledge or wilful blindness, the courts may consider whether the special disability in question would have been evident to any reasonable person.

In cases concerning a problem gambler, the knowledge requirement may be satisfied in several ways. As discussed above, gaming corporations possess information capable of identifying a 'very small group of customers' who are responsible for 57 per cent of the corporation's revenue. This information is obtained through data collection via respective loyalty membership schemes and is primarily used by gaming corporations for marketing purposes. It is suggested that if the venues in question are capable of targeting their marketing initiatives at heavy users in an attempt to entice them to remain at the machines longer ${ }^{157}$ they are clearly in possession of particular information that allows them to view which individuals fall within the 'heavy' losing limits. As the loyalty cards are issued to individuals with a unique identification code, it is submitted that the determination of a person's gambling habits should not be very difficult. ${ }^{158}$ Thus, although the gambling corporation is under no obligation to cease providing gambling services to the problem gambler, where such a card has been issued it cannot maintain that it

\footnotetext{
${ }^{155}$ Amadio (1983) 151 CLR 447, 474.

${ }^{156}$ Hart v O’Connor [1985] AC 1000, 1028. See also Anthony J Duggan, 'Unconscientious Dealing' in Patrick Parkinson (ed), The Principles of Equity (Lawbook, $2^{\text {nd }}$ ed, 2003) 147.

${ }^{157}$ Doughney, above n 35, 42.

${ }^{158}$ Verity Edwards, 'Pokie Loyalty Card "has limits”', The Australian (Sydney), 24 July 2008, 8.
} 
has no knowledge of the individual's 'special disability'. Moreover, it may be argued that, where a corporation makes no further inquiries into a 'heavy user's' gambling circumstances, the corporation renders itself wilfully blind to the individual situation.

In instances where the problem gambler has entered into a voluntary selfexclusion agreement, the knowledge requirement is even more easily satisfied. ${ }^{159}$ In such cases the gambling venue will possess actual knowledge of the individual problem gambler's special disability.

\section{Rebutting the Presumption}

Once it is established that a person is under a special disability, and that the stronger party has, knowing of that disability, continued to deal with the weaker party, the stronger party has the burden of proving that the transaction is fair. There is therefore, in effect, a rebuttable presumption that the transaction is unfair. In circumstances where a problem gambler has entered into an exclusion program, and the gaming venue has made reasonable efforts to exclude that person, it might be argued by the gaming venue that it has not in any way taken advantage of the problem gambler. Even where the gambler has entered the venue in breach of the agreement, provided the venue has reasonable measures in place to attempt to identify excluded patrons, the venue may argue that it has acted properly. In Foroughi Jacobson J held that the casino had not taken advantage of the plaintiff for the purposes of unconscionable conduct, effectively on the ground that the exclusion order against the plaintiff was properly made and managed. ${ }^{160}$ A different result might be reached where the system used by the gaming venue to monitor problem gamblers is inadequate.

A claim of unconscionable dealing might be made out where a gaming venue has, notwithstanding its knowledge of a person's gambling problems, offered inducements to that person to gamble. In Preston Wood CJ refused to strike out as untenable the plaintiff's claim that the casino took advantage of the plaintiff's vulnerability as a problem gambler by offering him inducements to gamble, and by offering free alcohol, even when he was already intoxicated. ${ }^{161}$ In Kakavas Harper $\mathrm{J}$ rejected the gaming venue's action to strike out a claim of unconscionable dealing where the plaintiff had been

\footnotetext{
159 Evaluation of Self-exclusion Programs, above n 8.

${ }^{160}$ Foroughi [2007] FCA 1503 (27 September 2007), [140].

161 See, Preston v Star City Pty Ltd [1999] NSWSC 1273 (1 February 2000).
} 
offered a series of inducements to gamble, despite having requested exclusion from the casino:

Looked at in the light of ordinary concepts of fair and just dealing, it is at least arguably wrong, morally and ethically, for a casino operator by conscious and deliberate policy to prey upon a patron known by the operator to be a compulsive gambler. ${ }^{162}$

Justice Harper also stated that, arguably, the plaintiff himself bore some responsibility for his losses and was not necessarily entitled to a remedy for his losses. ${ }^{163}$ However, it may be argued that the responsibility for the plaintiff, in light of his gambling problems, was assumed by the casino itself when it elected to assist the plaintiff in taking out a self-exclusion order.

Harper J eventually held that, although Kakavas was a 'pathological gambler', this did not affect his bargaining power with Crown. ${ }^{164}$ It was accepted that Kakavas' judgment 'when set against the judgment of the generality of members of the community, was overly influenced by a desire to gamble'. ${ }^{165}$ However, 'equality in bargaining power may be possible even if the plaintiff is under a disability'. ${ }^{166}$ For such reasons, inter alia, Kakavas' claim of unconscionable conduct failed. However, Harper $\mathrm{J}$ went on to state that this does not mean that a casino may never act unconscientiously in its dealings with a pathological gambler. Examples of instances where a casino does act unconscientiously were not proffered by his Honour.

\section{CONCLUSION}

Voluntary self-exclusion programs were introduced in response to the growing concern about the impact of problem gambling on individuals, families and the community. However, there is little evidence that such programs are effective. To the extent that the operation of the programs relies merely on 'facial recognition' to exclude patrons, then, inevitably, a proportion of excluded gamblers will be able to re-enter the gaming venue. This article has shown that there are few effective legal sanctions against a gaming venue that has failed to exclude a gambler after he or she enters the voluntary exclusion program. In part, this is as a result of the courts adopting

\footnotetext{
${ }^{162}$ Kakavas v Crown Ltd [2007] VSC 526 (8 December 2009), [22].

163 Ibid [21].

${ }^{164}$ Ibid [439].

${ }^{165}$ Ibid [440].

${ }^{166}$ Ibid.
} 
an unsympathetic view of problem gamblers and stressing the individual responsibility of the problem gambler. It has been suggested that this approach is not appropriate, in particular in cases where a problem gambler has taken steps to deal with the problem by entering into a self-exclusion program. In these circumstances it can be argued that the gaming venue has undertaken some responsibility for the well-being of the gambler, and created an expectation that it will, at the very least, do everything reasonably within its power to monitor and prevent the problem gambler from re-entering the venue for the purpose of gambling. As discussed above, it may be queried whether this responsibility is fulfilled.

If regulatory authorities are genuinely concerned with assisting problem gamblers through voluntary self-exclusion programs, then regulation of those programs need to be strengthened. There should be a requirement for regulatory review and reporting to an independent body of the success of the system. Moreover, gaming venues should be 'encouraged' to introduce better detection measures for gamblers, for example through the use of smart card technology. Further, in instances where a gambling corporation has failed to do everything reasonably within its power to monitor and prevent a selfexcluded problem gambler, it should be made liable for its actions. Currently the system is ineffective in achieving its objectives and its very existence may distract attention from genuine efforts to assist problem gamblers. 